THE WABASH CENTER

JOURNAL ON TEACHING
BOOK REVIEW

\section{Academic Growth in Higher Education: Questions and Answers}

\author{
Helena Pedrosa-de-Jesus and Mike Watts, editors \\ Boston, MA: Brill, 2019 \\ (xvii + 234 pages, ISBN 978-90-04-38932-8, \$55.00)
}

Reviewed By

Rebecca L. Copeland

Boston University School

of Theology
The Bologna Declaration of 1999 and ensuing protocols focus on promoting the quality of teaching and uniformity of standards for higher education in Europe. This collection of eighteen essays reflects advancements made in the Scholarship of Teaching and Learning (SoTL) and the rewards and challenges of transitioning to student-centered learning in higher education.

The academic growth mentioned in the title of this book refers to the promotion of academics' "knowledge related to teaching, learning, assessment, and feedback practices" (186-7). In a combination of critical reviews of current literature and novel case studies, the authors address issues raised by student-centered learning, including: conflicting ideas about the purposes of teaching, the changing demographics of university students, the differential impacts of research and teaching on academic careers, how universities can support academics through collaboration with SoTL researchers, and a number of teaching strategies and suggestions for how to train students to become lifelong learners.

The first part of the book examines recent issues in teaching and learning, including the impact a move towards universal higher education has on "opportunities of access" for nontraditional students (13), the political tensions involved in defining higher education as both "a human right and. . a commercial service" (25), and the development of SoTL as a field in and of itself. The second part examines pedagogical issues and experiments undertaken in Portugal, the United Kingdom, Qatar, and Japan, focusing on fostering student question-generation for learning, improving assessment techniques, and the roles of student cognitive styles in learning. The last part of the book reports the results of the Aveiro Project, "research endeavors from 2000-2015 at University of Aveiro, Portugal" (145). One of the few longitudinal studies in SoTL, these final chapters provide resources for considering both the challenges and benefits of undertaking the task of academic growth in higher education.

Although primarily focused on undergraduate education, and more specifically on the sciences, the chapters provide useful insights into teachers' own reflective practices (chapters 12 through 17), techniques for training students in appropriate question-generation (chapters 6, 9, 10, and 13), and different approaches to assessment (chapters 11 and 16). All of these are applicable or adaptable to theological education. Because these essays involve collaboration between academics and SoTL researchers, this volume would be most useful for administrators considering ways to enhance teacher effectiveness in their own institutions. The authors are transparent about the costs to academics of adopting many of the innovations described and the need for university support in the form of both amended expectations for career reviews and the support of departments that can provide SoTL expertise and assistance to academics in various fields. 